\title{
O JOGO: ESTRATÉGIA PARA HUMANIZAR A TECNOLOGIA
}

Fabián Mariotti'info@fabianmariotti.com

doi: 10.3900/fpj.7.4.278.p

Mariotti F. O jogo: estratégia para humanizar a tecnologia. Fit Perf J. 2008 jul-ago;7(4):278-80.

\section{RESUMO}

Esta proposta abrange a possibilidade de desenvolver as potencialidades psicomotoras, afetivas, criativas e recreativas do homem, com finalidades alheias a questões de índole pragmática da vida cotidiana. Através do jogo e seu benefício como meio para complementar as novas tecnologias, apoiando-se na convicção de que jogo e tecnologia possam se integrar na expressão lúdica, favorecendo as aprendizagens e, sobretudo, harmonizando as relações humanas. $\bigcirc$ método utilizado é o de sondagem, realizado pela implementação dentro do paradigma qualitativo da investigação descritiva. As técnicas e os meios realizados foram: pesquisas; entrevistas; análise de antecedentes de formação profissional; além de um trabalho de coletânea de dados em cursos ministrados pelo autor. O jogo: estratégia para humanizar a tecnologia, comporta um olhar diferente frente ao uso inteligente de produtos da tecnologia moderna, de maneira que estes fantásticos avanços não situem em um segundo plano a quantidade e a qualidade das relações humanas. A tecnologia, como outra visão didática, dá possibilidades de acesso ao conhecimento, neste caso a atividade lúdica como um meio que enriquece e humaniza.

\section{PALAVRAS-CHAVE}

Aprendizagem, Educação Infantil, Tecnologia.

1 Universidad Iberoamericana León - Guanajuato - México

Copyright(C 2008 por Colégio Brasileiro de Atividade Física, Saúde e Esporte

Fit Perf J | Rio de Janeiro | 7 | 4 | 278-284 | jul/ago 2008 
The game: A strategy to humANize the technology

\section{ABSTRACT}

This proposal comprises the possibility to develop psychomotor, affective, creative and recreational potentialities of the man, with purposes strange to queries of pragmatic natural disposition of the daily life. Through the game and its benefit as mean to complement the new technologies, leaning on the conviction that game and technology can become complete in the ludic expression, favoring the apprenticeships and, above all, harmonizing the human relations. The survey method was used, accomplished by the implementation inside of the qualitative paradigm of the descriptive investigation. The techniques and the accomplished means were: researches; interviews; analysis of antecedents of professional formation; besides a labor of data collection in courses supplied by the author. The game: strategy to humanize the technology, holds a different glance front to the intelligent usage of products of the modern technology, so that these fantastic advances do not place in a second plan the quantity and the quality of the human relations. The technology, as other didactic views, grants access possibilities to the knowledge, in this case the ludic activity as a mean that enriches and humanizes.

\section{KEYWORDS}

Learning, Child Rearing, Technology.

\section{El JUEGO: eStRATEgia PARA hUMANIZAR LA teCNOLOGíA}

\section{RESUMEN}

Esta propuesta abarca la posibilidad de desarrollar las potencialidades psico-motoras, afectivas, creativas y recreativas del hombre, con finalidades ajenas a cuestiones de índole pragmática de la vida cotidiana. A través del juego y su beneficio como medio para complementar las nuevas tecnologías, apoyándose en la convicción de que juego y tecnología pueden integrarse en la expresión lúdica, favoreciendo los aprendizajes y sobre todo, las relaciones humanas en armonía. El método utilizado es de sondeo realizado por la implementación dentro del paradigma cualitativo de la investigación descriptiva. Las técnicas y los medios realizados fueron encuestas, entrevistas y análisis de antecedentes de formación profesional. Y un trabajo de recopilación de datos en cursos que dictó el autor. El juego: estrategia para humanizar la tecnología, conlleva una mirada diferente frente al uso inteligente de productos de la tecnología moderna, de manera que estos fantásticos avances no ubiquen en un segundo plano la cantidad y calidad de las relaciones humanas. La tecnología como otra mirada didáctica da posibilidades de acceso al conocimiento, en este caso la actividad lúdica como un medio que enriquece y humaniza.

\section{PALABRAS CLAVE}

Aprendizaje, Crianza del Niño, Tecnologia.

\section{O jogo: estratégia para humanizar a tecnologia}

projeto de "O jogo como estratégia para humanizar a tecnologia" comporta um olhar diferente frente ao uso inteligente de produtos da tecnologia moderna, de maneira que estes fantásticos avanços não situem em um segundo plano a quantidade e a qualidade das relações humanas.

A tecnologia, como outra visão didática, dá possibilidades de acesso ao conhecimento, neste caso a atividade lúdica como um meio que enriquece e humaniza.

A comunicação interpessoal, o diálogo, o confronto fundado de idéias, o encontro tingido de afetividade, a capacidade de cooperar solidariamente e o exercício da empatia podem somar o equilíbrio ideal para mais uma vida rica, livre e plena. Por outra parte, mediante o jogo, é possível inferir desde a experiência corporal criativa, conceitos como força, inércia, movimento, equilíbrio, velocidade, coordenação, alternância, ritmo, acoplamento, etc., que se somam a aspectos éticos onde se recuperam valores e facetas estéticas vinculadas com o engenho, a fantasia e a inventividade, como, além disso, alguns jogos tendem a afinar a observação, incentivar a busca e desenvolver o sentido do humor.

Os jogos mais utilizados como estratégia pedagógica, na sua maioria, têm sustento na palavra (oral e escrita) e na imagem, o qual nos mostra uma marcada adesão 
àquilo que, para o docente, é material cotidiano de trabalho e, para o aluno, resultam percepções altamente valorizadas e exercitadas (vista-ouvido), que definem a nossa cultura audiovisual.

As opções de movimento corporal são as menos utilizadas. Tudo o que é relacionado com este tema costuma ser considerado privativo do professor de Educação Física, ou professora de nível inicial, sendo marcada uma divisa que parece arrastar ainda, no século XXl, a velha dualidade mente-corpo.

Outra causa da pouca adesão a jogos com movimentos e deslocamentos: o temor à desordem. Esta apreensão nasce, às vezes, do próprio docente e outras de diretivas de superiores que consideram o jogo como uma "perda de tempo".

A integração posterior à proposta lúdica do grupo de pares para o trabalho áulico dá um resultado positivo em 100\%. O jogo é elemento integrador: nesse sentido, a relação entre jogo e rendimento escolar resulta, conforme as expectativas, em qualidade de elemento mobilizador, especialmente para o trabalho grupal.

O desenvolvimento das capacidades criadoras dos alunos não se incentiva suficientemente. Em muitos casos, se lhes dão modelos ou "receitas" para trabalhar, sem abrir via à originalidade e à inventividade, como subestimando o abundante potencial do pensamento divergente.

Alguns docentes encontram inconvenientes para utilizar o jogo, pelos seguintes motivos:

- tempo limitado;

- espaços inadequados;

- falta de materiais e impossibilidade de conseguí-los;

- grupos com problemas de conduta;

- falta de aperfeiçoamento específico em um enfoque que veja o jogo como algo mais que um simples recreio;

- cobrança dos pais que pensam que o jogo é perda de tempo;

- questões de índole interna (necessidade de silêncio);

- condução que não visualiza a utilidade das atividades lúdicas.
São muito poucas as opções de capacitação ou aperfeiçoamento em matéria de propostas lúdicas na escola, exceto aquelas que se consideram indispensáveis no nível inicial, para adaptação, aprestamento, sensibilização ou estimulação adiantada. $\bigcirc$ jogo perdura nos primeiros anos da escola primária, mas depois praticamente desaparece, salvo opções criativas vinculadas com educação plástica e, em caso de existir, como opção extracurricular (arte cênica, danças ou artesanato).

A proposta original de jogos na escola e sua eleição, recriação ou adaptação a partir de outros jogos. Lembremos que o jogo imerso no sistema educacional é fundamentalmente um ato de comunicação e, como tal, deve ter características especiais: possuir dinamismo; responder a finalidades; ser adequado aos participantes; se ativar na hora certa; provocar respostas; e complementar a tecnologia. Sem que tudo dito deixe opaco o principal: a alegria de jogar em liberdade e de compartilhar experiências gratas e construtivas.

○ jogo, como estratégia didática dentro do marco da educação no processo de ensinar e de aprender, requer também sentido da oportunidade, abertura a possibilidades criativas e interativas - não violentas - e inserção em usos e costumes do próprio contexto lou descobrir a diversidade ao se trasladar a outros tempos e espaços). $O$ enriquecimento através do jogo deve se dar de maneira natural e não forçada, assim como se aprende quase sem o advertir ao observar a natureza ou a percepção inteligente de situações cotidianas e - olhar crítico aos conteúdos dos meios de massa de comunicação. Atualmente, o jogo, exceto em horas de Educação Física, aparece como prática freqüente no nível inicial e um a três graus, e decresce a partir de quatro em forma gradual. Na maior idade, é menor o emprego do recurso "jogo" como ferramenta pedagógica.

É necessário aproximar o lúdico ao docente, para fazer mais produtiva a tarefa de construir junto com os alunos novos conhecimentos e melhores atitudes para a vida de relação.

Recebido: 19/03/2008 - Aceito: 02/06/2008 